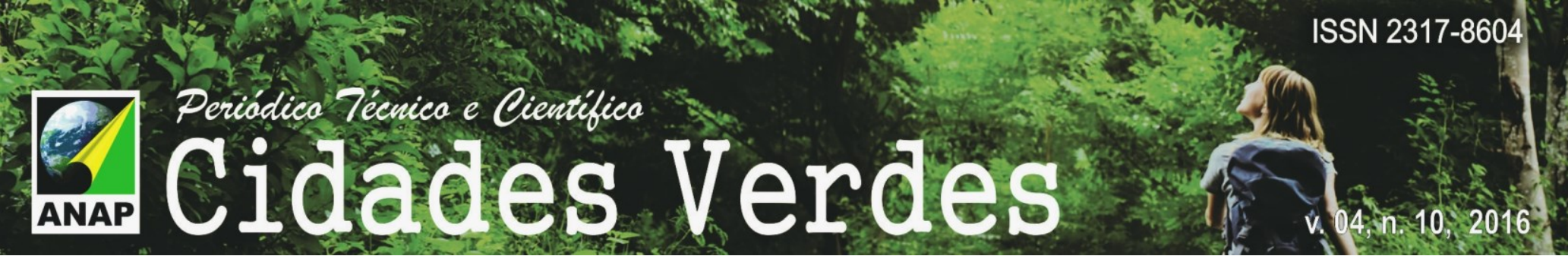

\title{
DIFERENTES SUBSTRATOS NO DESENVOLVIMENTO DE UM GRAMADO ORNAMENTAL PARA USO EM TELHADOS VERDES
}

Different substrates in the development of an ornamental lawn for use on green roofs

Distintos sustratos en el desarrollo de un césped ornamental para su uso en techos verdes

Patrick Luan Ferreira dos Santos Mestrando em Agronomia, UNESP/Ilha Solteira, Brasil patricklfsantos@gmail.com

Jéssica Pigatto de Queiroz Barcellos Doutoranda em Agronomia, UNESP/Botucatu, Brasil jessica.pqb@gmail.com

Regina Maria Monteiro de Castilho

Professora Assistente Doutora, UNESP/Ilha Solteira, Brasil castilho@agr.feis.unesp.br 


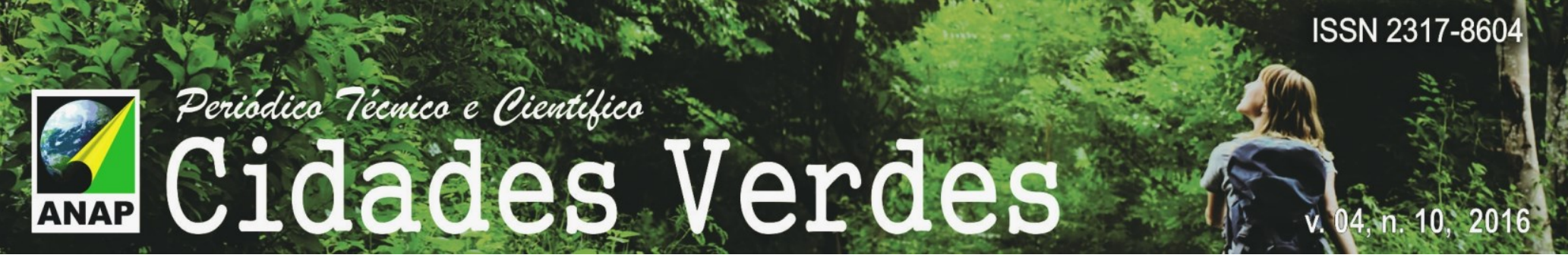

\section{RESUMO}

O uso de gramas ornamentais em telhados verdes é uma solução ambiental eficiente que está sendo adotada em muitas partes do mundo, contudo, essas devem ser instaladas em substratos adequados para seu desenvolvimento, assim $\mathrm{O}$ objetivo do trabalho foi avaliar o efeito de diferentes substratos no desenvolvimento de um gramado ornamental para seu uso em telhados verdes. O experimento foi conduzido a pleno sol na UNESP, Ilha Solteira/SP. Foram utilizados três componentes de substrato: areia, solo e matéria orgânica (grama batatais + esterco bovino decompostos por 1 ano), sendo que os Tratamentos foram: T1- solo; T2- solo + areia (2:1); T3- solo + areia (1:1); T4solo + matéria orgânica (1:1); T5- solo + matéria orgânica (2:1); T6- solo + matéria orgânica + areia (2:1:1); T7- solo + matéria orgânica + areia (1:1:1) e T8- areia + matéria orgânica (1:2), instalados em conteiners de 8,46 L, e posteriormente implantada a grama esmeralda sobre cada tratamento, sendo realizadas as análises ficas e temperatura de cada substrato, teor de clorofila das folhas e massa fresca e seca da parte aérea. Conclui-se que substratos que apresentaram matéria orgânica em sua composição apresentaram os melhores resultados, sendo esses os ideais para uso em telhados verdes, e ainda a utilização apenas de solo implica em baixo desenvolvimento do gramado ao longo do tempo.

PALAVRAS-CHAVE: Zoysia japonica Steud. Matéria orgânica. Grama esmeralda.

\section{ABSTRACT}

The use of ornamental grasses in green roofs is an efficient environmental solution that is being adopted in many parts of the world, however, these must be installed on suitable substrates for its development and the objective of this study was to evaluate the effect of different substrates in the development an ornamental lawn for use on green roofs. The experiment was conducted in full sun at UNESP, Ilha Solteira / SP. We used three substrate components: sand, soil and organic matter (bahiagrass + cattle manure decomposed for 1 year), and the treatments were: T1- soil; T2- soil + sand (2:1); T3- soil + sand (1:1); T4- soil + organic matter (1:1); + T5- soil + organic matter (2:1); T6- soil + organic matter + sand (2:1:1); T7- soil + organic matter + sand (1:1:1) and T8- sand + organic matter (1:2) installed in containers of $8.46 \mathrm{~L}$ and subsequently implanted zoysia Grass on each treatment being carried the physics analysis and temperature of each substrate, chlorophyll content of leaves and fresh weight and shoot dry. It is concluded that substrates that showed organic matter in their composition showed the best results, and these ideal for use in green roofs, and still use only soil implies low development of the lawn over time.

KEYWORDS: Zoysia japonica Steud. Organic matter. zoysia grass.

\section{RESUMEN}

El uso de cespedes ornamentales en los techos verdes es una solución eficaz del medio ambiente que se está adoptando en muchas partes del mundo, sin embargo, éstos deben estar instalados en sustratos adecuados para su desarrollo y el objetivo de este estudio fue evaluar el efecto de diferentes sustratos en el desarrollo de un césped ornamental para su uso en techos verdes. El experimento se llevó a cabo a pleno sol en la UNESP, Ilha Solteira/SP. Utilizamos componentes de tres sustratos: arena, tierra y materia orgánica (pasto bahía + estiércol de ganado descompuesto por 1 año), y los tratamientos fueron: T1 suelo; T2 suelo + arena (2:1); T3 suelo + arena (1:1); T4 + materia orgánica del suelo (1:1); + Suelo T5 materia orgánica (2:1); T6- suelo + materia orgánica + arena (2:1:1); T7 suelo + materia orgánica + arena (1:1:1) y arena + materia orgánica T8 (1:2) instalados en contenedores de 8,46 L y posteriormente implantado hierba esmeralda en cada tratamiento, fueron realizadas análisis físicas y la temperatura de cada sustrato, contenido de clorofila de las hojas y el peso fresco y seco de la parte aérea. Se concluye que los sustratos que mostraron la materia orgánica en su composición mostraron los mejores resultados, y estos son ideales para uso en techos verdes, y todavía utilizando solamente suelo implica un bajo desarrollo del césped con el tiempo.

PALABRAS CLAVE: Zoysia japonica Steud. Materia orgánica. Hierba esmeralda. 


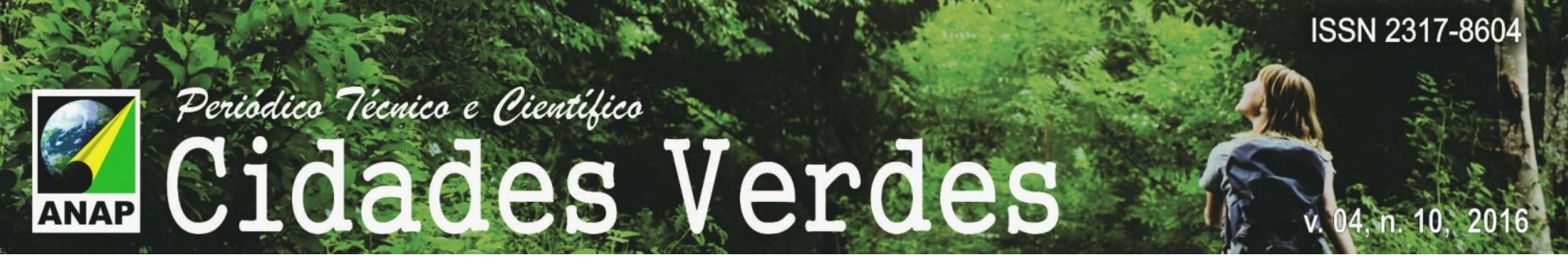

\section{INTRODUÇÃO}

O crescimento populacional, o adensamento de construções e a mudança radical da paisagem, têm caracterizado o processo de urbanização em escala mundial nas últimas décadas (ARAUJO, 2007). Segundo Silva, (2011), a questão da importância entre a conservação ambiental e o desenvolvimento populacional foi lançada com a Conferência das Nações Unidas sobre o Meio Ambiente e Desenvolvimento Humano, a RIO 92. Com a inovação tecnológica o mercado construtivo tem buscado novas possibilidades para diminuir o impacto ambiental de todo o país.

Para minimizar esses efeitos e compensar o meio ambiente o telhado verde é uma solução eficiente que está sendo adotada em muitas partes do mundo, principalmente na Europa (CEOTTO, 2006). Os telhados verdes são caracterizados como toda cobertura ou telhado, que agrega em sua composição, uma camada de solo ou substrato e outra de vegetação. Com finalidades estéticas de valorização do espaço urbano e para melhoria do conforto ambiental, essas áreas verdes podem servir também para detenção do escoamento superficial, minimizando as enchentes urbanas. (ARAUJO, 2007).

De tal modo, espécies vegetais, como gramados, são excelentes opções para uso em telhados verdes, sendo a grama esmerada (Zoysia japonica Steud.) a mais utilizada como função ornamental em todo o Brasil (GODOY et al. 2012), e sua utilização como cobertura vegetal em telhados verdes vem crescendo nos últimos anos (ARAUJO, 2011).

Fato esse se deve, pois essa espécie é capaz de formar gramados perenes, amplamente adaptados a diversos tipos de solos e ambientes, sendo identificadas pelo seu uso potencial como uma grama de baixa manutenção. Ainda é considerada de maior importância para o mercado da grama, sendo a mais comercializada no Brasil, desde a região Sul até a região Nordeste (GODOY et al., 2012), e apresenta diversas vantagens no uso do paisagismo em cidades.

De acordo com a Associação Internacional dos Produtores de Grama um gramado bem mantido proporciona um local confortável e seguro para diversão e prática de esportes; libera oxigênio (cerca de $230 \mathrm{~m}^{2}$ de área gramada libera $\mathrm{O}_{2}$ suficiente para quatro pessoas); refresca o ar e com isto contribui para os esforços de reduzir a tendência de aquecimento global (em um dia quente de verão um gramado apresenta $16,5^{\circ} \mathrm{C}-7,8^{\circ} \mathrm{C}$ a menos que um asfalto e um solo sem vegetação); controla a poluição do solo (a rizosfera serve com um filtro absorvendo o que passa por ela) e pode elevar o preço de um imóvel em até 15\% (OLIVEIRA, 2012).

Devido à alta produtividade e a não mobilização do solo em áreas gramadas, estas podem ter um alto potencial para sequestrar o $\mathrm{CO}_{2}$ atmosférico e atenuar o efeito estufa (GODOY, 2005). Qian e Follet (2002) estudaram a capacidade de sequestro de carbono por solos com gramado, verificaram que, em média, cerca de $1 \mathrm{Mg} \mathrm{ha-}{ }^{1}$ ano $^{-1}$ de C é sequestrado nos solos.

Ainda áreas gramadas podem contribuir para amenizar os efeitos do fenômeno de ilha de calor, onde superfícies de asfalto ou concreto absorvem a energia solar, ocasionando um aumento na temperatura do local. Sendo assim, áreas gramadas eliminam este efeito através da evapotranspiração, diminuindo a temperatura em até 15ㄷ (CAMPOS; CASTILHO, 2005). E de acordo com a University of Minnesota (2006), a utilização de grama em torno de uma casa 


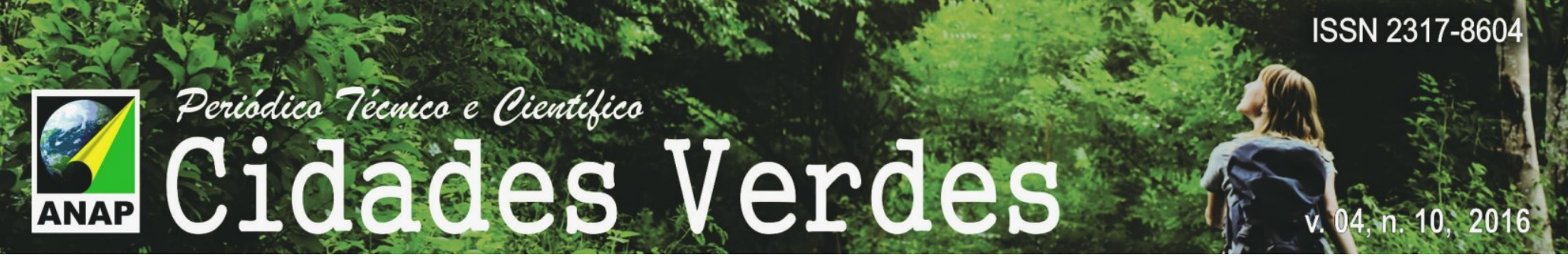

Tabela 1: Análise química do solo. UNESP, Ilha Solteira - SP, 2012.

\begin{tabular}{llllllllllll}
\hline & $\mathbf{p H}$ & $\mathbf{C a}$ & $\mathbf{M g}$ & $\mathbf{K}$ & $\mathbf{A l}$ & $\mathbf{H}+\mathbf{A l}$ & $\mathbf{S B}$ & $\mathbf{C T C}$ & $\mathbf{P}$ & $\mathbf{M O}$ & $\mathbf{V}$ \\
\hline & $\mathrm{H}_{2} \mathrm{O}$ & $---\mathrm{mg} \mathrm{dm}^{-3}$ & $\mathrm{~g} \mathrm{dm}^{-3}$ & $\%$ \\
\hline Solo & 5,0 & 24 & 1,0 & 0,7 & 0,0 & 22 & 25,9 & 47,9 & 27 & 31 & 54 \\
\hline
\end{tabular}

Fonte: próprio autor, Método de ensaio: método da resina citado por Raij (1987).

O composto utilizado foi decomposto por 1 ano, sendo formado das folhas de grama batatais e esterco de curral (1:1); a areia média lavada foi adquirida no comercio local. O manejo da irrigação foi realizado diariamente de forma manual, sendo que os contêineres receberam água até a saturação, para que o fator água não interferisse nos resultados do experimento. Aos 170 dias após a implantação do experimento, todos os tratamentos, receberam adubação de manutenção com o fertilizante comercial Forth Jardim ${ }^{\circledR}$ na dose de $125 \mathrm{~g} / \mathrm{m}^{2}$.

Foi realizada a análise física de cada tratamento, avaliando-se macro e microporosidade, porosidade total e densidade dos substratos, para isso utilizou-se de uma amostra deformada. Análise da temperatura de cada substrato seco com um termômetro de haste em intervalos variando em intervalos de 5 a 13 dias, iniciando a partir de 164 dias após a implantação do experimento, devido ao gramado já estar estabelecido e em pleno desenvolvimento.

Teor de clorofila das folhas, obtido com o auxílio do clorofilômetro manual Chlorophyll Content Meter (CCM 200), sendo para tanto coletadas de 4 a 6 folhas de grama-esmeralda de cada contêiner, estas são dispostas no clorofilômetro de modo a cobrir inteiramente o detector, sem que as folhas fossem sobrepostas.

Massa fresca e massa seca das folhas, foram coletadas todas as folhas do gramado de cada contêiner, sendo essas colocadas em sacos de papel previamente tarados e identificados, em seguida, foi determinada a massa fresca, sendo a massa seca determinada após alocação das amostras em estufa, a $60^{\circ} \mathrm{C}$, e pesadas após 3 dias, quando estabilizada a massa. Todas as pesagens foram realizadas em balança de 0,01 de precisão. A coleta realizou-se 215 dias após a instalação do experimento.

Os resultados foram analisados através de análise de variância (ANAVA) e teste de Tukey ao para análise nível de $5 \%$ de probabilidade para comparação de médias, utilizando-se do programa SISVAR dos dados (FERREIRA, 2003).

\section{RESULTADOS}

A Tabela 2 apresenta os dados de macro, micro, porosidade total e densidade dos substratos. 


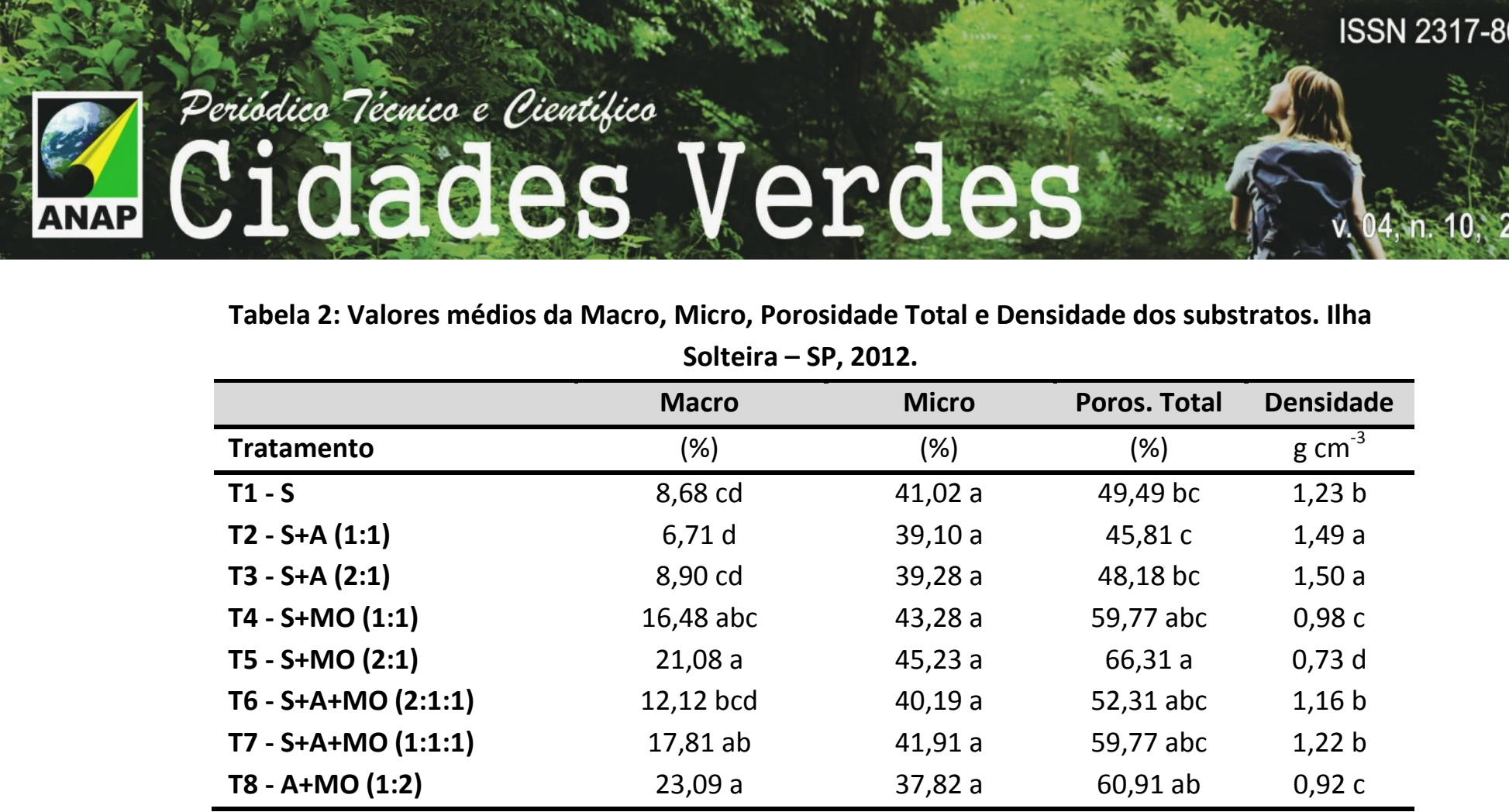

Fonte: próprio autor, Médias seguidas de mesma letra não diferem entre si ao nível de $5 \%$ de significância pelo teste Tukey. $\mathrm{S}=$ solo; $\mathrm{A}=$ areia; $\mathrm{MO}=$ matéria orgânica.

Nota-se que para a Macroporosidade, T8 apresentou o melhor resultado, com 23,09\% de macroporos, sendo estatisticamente igual a T5 e T7. O menor valor foi observado em T2 (6,71\%), sendo que este não difere de T1, T3 e T6. Ao avaliar a microporosidade, observa-se que não houve diferença estatística entre nenhum dos tratamentos, sendo que T5 apresentou o maior valor e T8 o menor. Para a porosidade total, T5 composto de S+MO (2:1), apresentou o melhor resultado, sendo este estatisticamente igual a T4, T6, T7 e T8, já T2 apresentou o menor valor. Na densidade total dos substratos nota-se que a menor densidade foi observada por T5, sendo este o substrato menos compactado e diferindo de todos os demais tratamentos, já T3 apresentou o maior valor de densidade, sendo estatisticamente igual apenas a T2. Relação inversa nota-se com relação a porosidade total e densidade, ode quanto maior a densidade dos substratos, menor será sua densidade.

De acordo com Duble (2011) e Kiehl (1979), valores referentes à macroporosidade, inferiores a $10 \%$ de macroporos no solo são prejudiciais ao crescimento radicular. E nota-se no presente trabalho T1, T2 e T3 estão abaixo desse valor.

Para Kiehl (1979), um solo ideal é aquele que apresenta $1 / 3$ de macroporos dos $0,50 \mathrm{~m}^{3} / \mathrm{m}^{3}$ ocupados pelos espaços do solo, isto é, $0,17 \mathrm{~m}^{3} / \mathrm{m}^{3}$, ou, $17 \%$ de macroporos. Sendo assim, constata-se que, os tratamentos $\mathrm{T7}$ é o substrato a obter o resultado considerado ideal, apenas de T4 se aproximar do valor, e T8 se encontrar acima do citado. Já os demais tratamentos, estão com os valores abaixo do exposto.

T4, T5, T6, T7 e T8 são os substratos que contém matéria orgânica em sua composição, e segundo Camillotti et al. (2006), o uso desse composto pode resultar em um aumento da macroporosidade do solo, como observado nesse trabalho.

Deve-se considerar que a avaliação foi realizada anteriormente a instalação de qualquer espécie vegetal e, portanto, anterior à ação das raízes; assim, espera-se que após a instalação das plantas, esses valores sofram alterações, tendo que ter em conta o manejo que será adotado para a cultura instalada. 


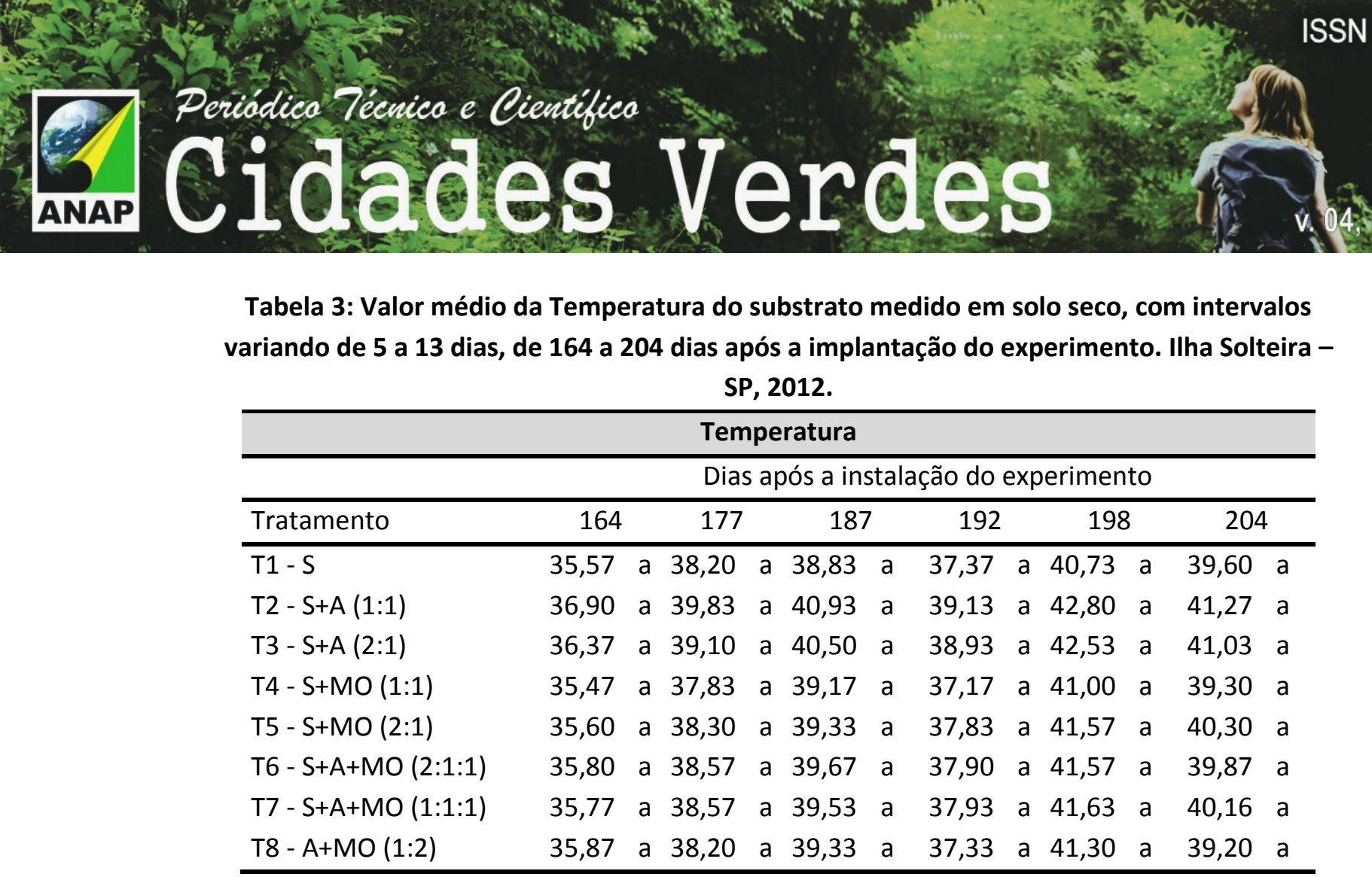

Fonte: próprio autor, Médias seguidas de mesma letra não diferem entre si ao nível de $5 \%$ de significância pelo teste Tukey. $\mathrm{S}=$ solo; $\mathrm{A}=$ areia; $\mathrm{MO}=$ matéria orgânica.

Para todas as avaliações realizadas não houve diferença estatística entre as médias para os diferentes tratamentos. Numericamente, entretanto, T2 apresentou as maiores médias de temperatura ao longo das avaliações, sendo que o tratamento 3 acompanhou os resultados do tratamento 2. E de maneira geral, os substratos compostos por matéria orgânica apresentaram os menores resultados para as avaliações realizadas com relação a temperatura dos substratos.

Segundo Unruh (2004), muitos eventos físicos, químicos e biológicos que ocorrem no solo são fortemente dependentes da temperatura. A temperatura do solo é afetada por: condições atmosféricas (temperatura do ar, umidade, vento e radiação solar); absorção térmica e condutividade do solo: que é uma função de cor, umidade e conteúdo de matéria orgânica do solo. Geralmente solos mais escuros, com alto teor de matéria orgânica são mais eficientes em absorver calor da atmosfera. A absorção de calor ocorre mais rapidamente em solos secos, porque em solos úmidos necessita-se de um calor adicional para aquecer a água; esse ultimo fator pode ter contribuído para que os tratamentos que possuíam matéria orgânica em sua composição, apresentassem as menores médias de temperatura do solo, tendo em vista que, compostos como matéria orgânica possuem grande capacidade de retenção de água em função da capacidade de reter íons nutrientes e de troca de elétrons, aumentando consideravelmente o teor de umidade do solo (BRADY, 1989).

Ainda, segundo Unruh (2004) a cobertura de plantas também influencia na temperatura do solo, como concluiu Beatrice (2011) em seu experimento, ao observar que solos de menor espessura, como os do presente experimento, são mais dependentes de cobertura vegetal para minimizar seu aquecimento, e isso, segundo o autor, ocorre devido ao sombreamento causado pela vegetação e também devido a formação de uma câmara de ar sobre o mesmo, sendo que os solos com maior espessura possuem menor dependência da vegetação. Esse 


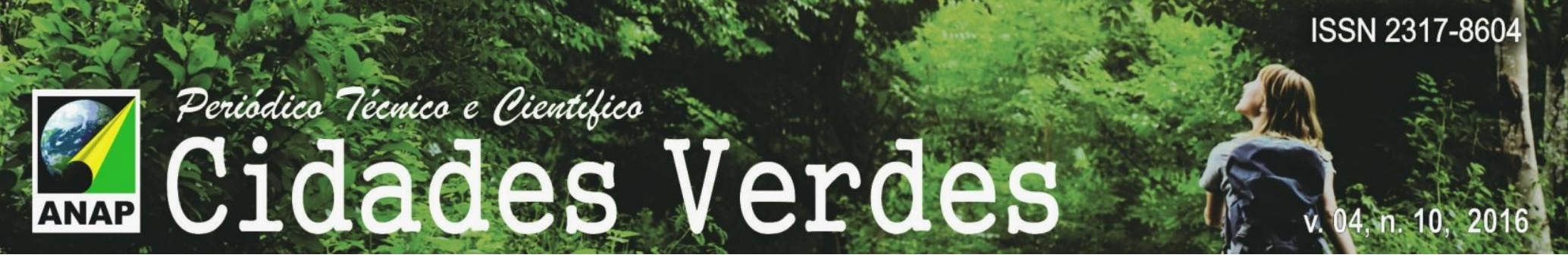

estatisticamente diferente de T4, T7 e T8, ambos apresentaram os menores resultados. Por fim, aos 211 dias após a instalação do experimento, observa-se que não houve diferença estatística significativa para nenhum dos tratamentos, contudo os maiores valores foram apresentados em T1 e T5, e o menor em T7.

De acordo com Bowman, Cherney e Rufty Junior (2002), o teor de clorofila nas folhas reflete indiretamente a quantidade de $\mathrm{N}$ absorvida pelas plantas, sendo o nitrogênio elemento mineral requerido em maiores quantidades pelas gramas e quando mantido em níveis adequados promove o vigor, a qualidade visual e a recuperação de injúrias. Pelos resultados obtidos no presente trabalho, referente ao teor de clorofila infere-se que pode haver uma deficiência de nitrogênio, e por consequência havendo depauperamento do gramado, pois segundo Lima et al. (2008), este índice é indicativo de baixo estado nutricional em nitrogênio, e quando os autores, usando diferentes doses de fonte de nitrogênio, verificaram aumento nas leituras em clorofilômetro em decorrência do aumento dos teores de nitrogênio, conferindo maior intensidade de cor verde e maior concentração de $\mathrm{N}$, atingindo uma leitura máxima de $38 \mathrm{ICC}$, no presente trabalho, nenhum dos tratamentos atingiu o referido valor.

Dinalli et al (2010) propuseram valores de teores de clorofila em grama esmeralda compreendidos entre $14,7-21,3 \mathrm{CCl}$, semelhantes aos encontrados no presente trabalho; Carozelli (2011), em trabalhos com campos de futebol, com grama esmeralda, encontrou valores entre 9,9 a 18,93 ICC. Já Amaral (2009), em trabalho com grama batatais, obteve resultados médios de 17 ICC. Posto que esses trabalhos também foram desenvolvidos na cidade de llha Solteira, nota-se que os valores obtidos no ensaio corroboram com os citados acima.

Dinalli et al (2012), avaliando o índice de clorofila em grama esmeralda, em função da aplicação de fontes de nitrogênio, na cidade de Ilha Solteira, observaram valores de teor de clorofila no intervalo de 17,9 a 19,4 ICC, corroborando com os valores encontrados no presente trabalho após realizada a adubação de manutenção.

Entretanto, para Carrow, Waddingtion e Rieke (2001), os valores satisfatórios para grama esmeralda estão acima de 37 ICC, e para Lima et al (2008), até 38 ICC, ou seja, valores muito superiores ao encontrado no presente trabalho.

Segundo Godoy e Villas Bôas (2003), no Brasil, nas áreas residenciais, industriais e públicas, o principal objetivo dos gramados é o aspecto estético (visual) sendo muito importante gramados com coloração verde intensa e boa densidade (gramado fechado, sem falhas, onde aparece o solo), o mesmo se aplica para uso das gramas em telhados verdes, ou seja, quanto maior o índice de conteúdo de clorofila, maior o verde da grama, e maior a capacidade da mesma realizar processos fotossintéticos.

A Tabela 5 apresenta os valores médios de massa fresca e seca da parte aérea das folhas de grama esmeralda, coletadas 215 após a instalação do experimento. 


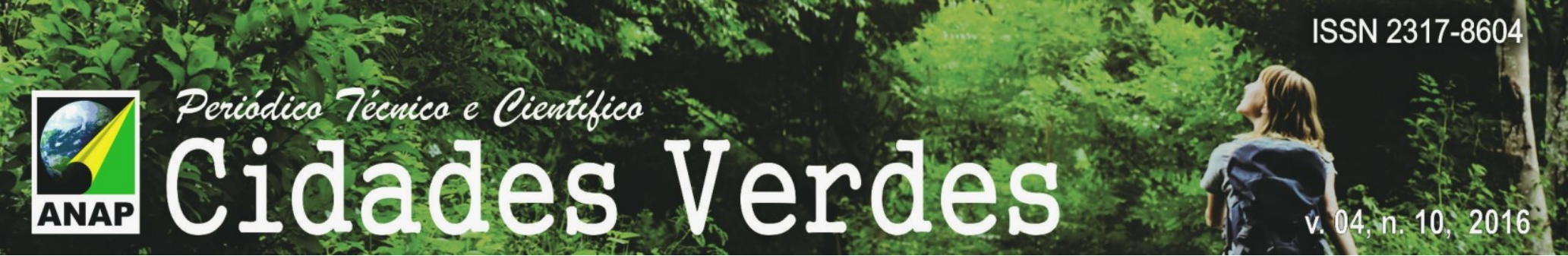

\section{CONCLUSÃO}

Os substratos que apresentaram matéria orgânica em sua composição apresentaram os melhores resultados para os parâmetros avaliados, mostrando assim que o uso desse composto na instalação de áreas gramadas em telhados verdes é uma grande opção para o bom desenvolvimento dessa espécie.

O Uso apenas de solo em telhados verdes, pode ocasionar altas temperaturas e elevados níveis de compactação o que prejudica o desenvolvimento da grama ao longo do tempo.

Maiores incrementos de massa fresca e seca implicam em maiores custo de manutenção de corte das gramas, o que para telhados verdes de baixa manutenção não vem a ser desejável.

\section{REFERÊNCIAS BIBLIOGRÁFICAS}

AMARAL, J. A. Efeito de diferentes adubos comerciais na revitalização de grama batatais (Paspalum notatum Flügge). 2009. 43f. Trabalho de Conclusão de Curso (Graduação em Agronomia) - Faculdade de Engenharia, Universidade EstadualPaulista, Ilha Solteira, 2009.

ARAÚJO, S.R. As funções dos telhados verdes no meio urbano, na gestão e no planejamento de recursos hídricos. Monografia (Engenharia Florestal) - Instituto de Florestas/Universidade Federal Rural do Rio de Janeiro, Seropédica/RJ, 2007. 28 p.

BAVER, L.D. Soil physics. California: J. Wiley \& Sons, 1956.

BEATRICE, C. C. Avaliação do potencial de uso de três espécies vegetais como cobertura leve de telhados em edificações. 2011.125p. Dissertação de mestrado (Mestrando em Ciências da Engenharia Ambiental) - Escola de Engenharia de São Carlos - USP, São Carlos, 2011.

BOWMAN, D.C., CHERNEY, C.T., RUFTY JUNIOR, T.W. Fate and transport of nitrogen applied to six warmseasenturfgrasses. Crop Science, v.42, p.833-841, 2002.

BRANDY, N. C.; WEIL, R. R. Natureza e propriedade dos solos. 70 edição, Rio de Janeiro, 1989. 898 p.

CAMILOTTI, F. et al. Atributos físicos de um latossolo cultivado com cana-de-açúcar após aplicações de lodo de esgoto e vinhaça. Eng. Agríc. vol.26 n.3 Jaboticabal Sept./Dec. 2006.

CAMPOS, W. N. de ; CASTILHO, R. M. M. . Amplitude térmica entre pavimentos do tipo. Anais... In: XVII Congresso de Iniciação Científica da UNESP. 2005, Ilha Solteira - SP. XVII Congresso de Iniciação Científica da UNESP, 2005.

CAROZELLI, P. A. Avaliação da compactação de gramados de campos de futebol em llha Solteira - SP. 2011. 33p. Trabalho de Conclusão de Curso (Graduação em Agronomia) - Faculdade de Engenharia, Universidade EstadualPaulista, Ilha Solteira, 2011.

CARRIBEIRO, L. S. Potencial de água no solo e níveis de compactação para o cultivo de grama esmeralda. 2010. Dissertação (Mestrado em Agronomia/Irrigação e Drenagem) - FCA / UNESP, Botucatu, 2010.

CARROW, R. N.; WADDINGTON, D. V.; RIEKE, P. E. Turfgrass soil fertility and chemical problem: assessment and management. Chelsea: Ann Arbor, 2001.

CEOTTO, L.H. Construção Civil e o Meio Ambiente: 1ำ parte. Notícias da Construção, São Paulo, n 51, nov. 2006.

DINALLI, R. P.; BUZETTI, S.; CASTILHO, R. M. M.; DENADAI, M. S.; CELESTRINO, T. S. Reabilitação de gramado de Zoysia dPica Steud., em IlhaSolteira/SP. In: Reunião Brasileira de Fertilidade do Solo e Nutrição de Plantas, 29. , 2010. Guarapari. Resumos...São Paulo. 2010. 


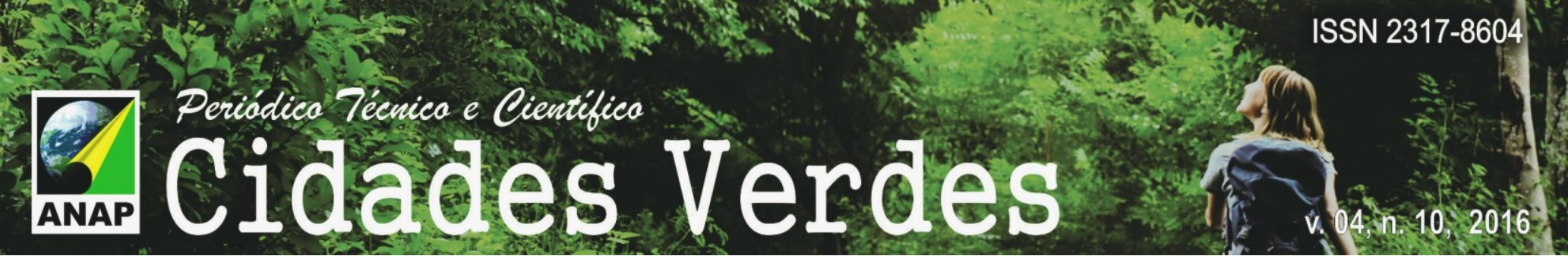

DINALLI, R. P.; BUZETTI, S.; CASTILHO, R. M. M.; GAZOLA, R. N.; CELESTRINO, T. S. Índice de Clorofila na folha de grama esmeralda em função da aplicação de fontes de N. In: VI SIGRA- Simpósio de Gramados - Anais...UNESPFaculdade de Ciências Agronômicas, Botucatu, SP, 15 e 16 de maio de 2012.

DUBLE, R. L. Water management on turfgrasses. 2009. Disponível em: <http://aggiehorticulture.tamu.edu/archives/parsons/turf/publications/water.html>. Acesso em: 11 nov. 2012.

DUBLE, R. Turfgrass rootzones. 2011 Disponível em: < http://www.turfdiag.com/turfgrassrootzones.htm >. Acessoem: 11 nov. 2012.

EMBRAPA, Empresa Brasileira de Pesquisa Agropecuária. Sistema Brasileiro de classificação de solos. 2 ed. Rio de Janeiro - RJ: Embrapa - Centro Nacional de Pesquisa de Solos, 1997. 212 p.

FERREIRA, D. F. SISVAR. Sistema de análise de variância para dados balanceados. Lavras: UFLA, 2000.

GODOY, L. J. G. Adubação nitrogenada para produção de tapetes da grama Sto. Agostinho e Esmeralda. 2005. Tese (Doutorado em Agronomia/Agricultura) - FCA/ UNESP, Botucatu, 2005.

GODOY, L. J. G. de; VILLAS BÔAS, R. L.; BACKES, C.; SANTOS, A. J. M. Nutrição, Adubação e Calagem para produção de gramas. $1 \mathrm{Ed}$. FEPAF, 2012. 146p.

GODOY, L.J.G.; VILAS BÔAS, R. L. Nutrição de gramados. In: SIMPÓSIO SOBRE GRAMADOS - SIGRA, 1. Botucatu: Departamento de Recursos Naturais, 2003. (1 CD-ROM).

GOEDERT, W. J.; SCHERMACK, M. J.; FREITAS, F. C. Estado de compactação do solo em áreas cultivadas no sistema de plantio direto. Pesquisa Agropecuária Brasileira, Brasília, v. 37, n. 2, p. 223-227, 2002.

GONÇALVES, J.L.M.; SANTARELLI, E.G.; MORAES NETO, S.P. \& MANARA, M.P. Produção de mudas de espécies nativas: substrato, nutrição, sombreamento e fertilização. In: GONÇALVES, J.L.M. \& BENEDETTI, V., eds. Nutrição e fertilização florestal. Piracicaba, IPEF, 2000. p.309-350.

GONÇALVES, J.L.M.; STAPE, J. L. Conservação e cultivo de solos para plantações florestais. Piracicaba: Instituto de Pesquisas e Estudos Florestais. 2002.

KAISER, D.R. et al. Temperatura do solo afetada por diferentes estados de compactação. Disponível em: <http://w3.ufsm.br/ppgcs/congressos/XIV_Reuni\%e3o_Brasileira_Cuiab\%e1/18.pdf> Acesso em: 10/03/2012.

KIEHL, E.J. Manual de edafologia: Relação solo-água-planta. São Paulo, Agronômica. Ceres, 1979.

LIMA, C.P.; LOPES, D. A.; VILLAS BÔAS, R. L.; FERNANDES, D.M.; BACKES, C. Medidas de intensidade de coloração verde das folhas, determinadas por dois clorofilômetro em campo de produção de grama esmeralda adubada com doses de ajifer. Tópicos Atuais em Gramados. Ed. FEPAF, Botucatu, p. 170 - 174. 2008.

LOPES, J.L.W.; GUERRINO, I.A.; SAAD, J.C.C.; SILVA, M.R. Atributos químicos e físicos de dois substratos para produção de mudas de eucalipto. Cerne, Lavras, v. 14, n. 4, p. 358-367, out./dez. 2008.

OLIVEIRA, M. R. de. Aplicação de escória de aciaria e calcário no solo e desenvolvimento do primeiro ciclo da grama bermuda. 2012. Dissertação (Mestrado em Agronomia/Agricultura) - FCA / UNESP, Botucatu, 2012.

PESSOA, T. O. A.; CAMPOS, T. M. P.; ANTUNES, F. S.; DUARTE, A. P. L. Avaliação da influência da mineralogia, índice de vazios e teor de umidade em propriedades térmicas de solos. Disponível em: <http://www.maxwell.lambda.ele.puc-rio.br/Busca_etds.php?strSecao=resultado\&nrSeq=9507\%401> Acesso em: $10 / 03 / 2012$

QIAN, Y.L.; FOLLETT, R.F. Assessing soil carbon sequestration in turfgrass systems using long-term soil testing data. Agronomy Journal, v.94, p.930-935, 2002.

RAIJ, B. van et al. Análise química do solo para fins de fertilidade. Campinas: Fundação Cargill, 1987. 170p. 


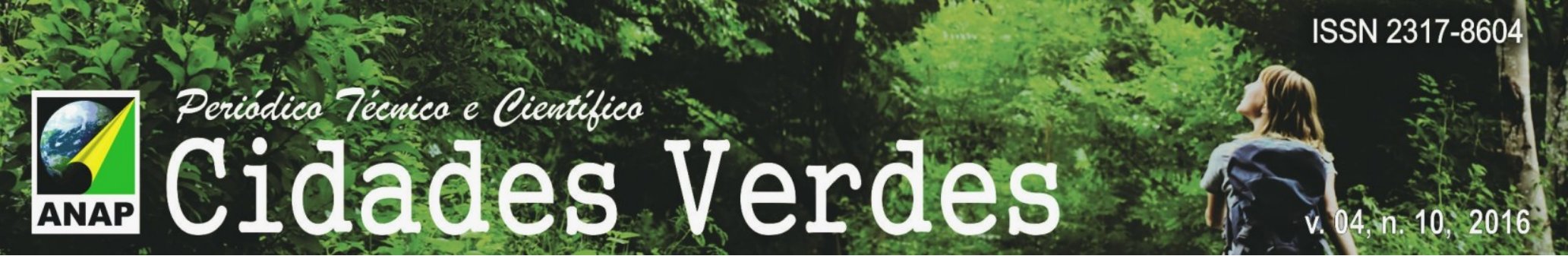

SANTOS, P. L. F. Influência da compactação e da adubação de diferentes substratos no desenvolvimento da grama esmeralda. Trabalho de conclusão de curso (Agronomia) - FEIS/UNESP, Ilha Solteira/SP, 2014.

SILVA, N.C. Telhado verde: sistema construtivo de maior eficiência e menor impacto ambiental. Monografia (Especialização em Construção Civil) - UFMG, Belo Horizonte-MG, 2011. 63 p.

UNIVERSITY OF MINESOTA. Turfgrass Benefits Related to Temperature Modification. Disponível em: <http://www.sustland.umn.edu/maint/benefits_3.html> Acesso em: 20 de fevereiro de 2013.

UNRUH, J.B. Biologia de gramas de estação quente - II SIGRA - Simpósio sobre Gramados - "Manejo de Gramas na Produção e em Gramados Formados" - Anais... UNESP - Faculdade de Ciências Agronômicas, Botucatu, SP, 2004. 